\title{
The acceptability, knowledge and perceptions of pregnant women toward HIV Testing in pregnancy at Ilembe District
}

\author{
FN Dube, M Cur \\ University of KwaZulu-Natal
}

ZZ Nkosi, PhD candidate, M Cur

Lecturer: School of Nursing, University of KwaZulu- Natal

Key Words:

Acceptability, Knowledge, Perceptions, Pregnant women, HIV Testing
Correspondence address:

Ms ZZ Nkosi

School of Nursing

University of KwaZulu- Natal

Howard College Campus

Durban

4001

Tel (031) 260-2901

Fax : (013) 260-2855

E-mail : nkosizz@ukzn.ac.za

\section{Abstract: Curationis 31(3): 12-20}

This research study aimed to investigate the acceptability, knowledge and perceptions of pregnant women toward HIV testing in pregnancy in Ilembe District.

An exploratory research design guided the study. A systematic random sampling was used to select pregnant women who were attending the ante-natal clinic for the first time in their current pregnancy.

Self-administered questionnaires with close-ended questions were used in the collection of data. The questions included the women's demographic details, their views of HIV testing, knowledge and as well as their acceptability of HIV testing. Forty questionnaires were distributed and they were all returned. A quantitative method was used to analyse the data. The findings of the study revealed that $45 \%$ of the women in the sample were relatively young (18-25 years) and most of them ( $90 \%)$ were unmarried . The majority of women $(92.5 \%)$ said testing was a good idea and $85 \%$ said it was necessary. However only $52.5 \%$ said they would opt for HIV testing. The uptake of HIV testing was found to be low.

Eighty-seven and a half percent $(87.5 \%)$ of the women in the sample were of the opinion that HIV testing in pregnancy was of benefit to the mother and her baby. Women in the study were generally found to have a good understanding and good perceptions towards HIV testing in pregnancy, but this was not consistent with their behaviour.

\section{Background}

AIDS is regarded as a serious health crisis because of the large number of people who are dying of complications related to HIV/AIDS. Globally there are 33 million people who are infected with HIV and the number of people living with HIV in Africa has skyrocketed to 22 million (UNAIDS, 2008). South Africa is now faced with the largest and fastest growing HIV epidemic in Africa and the world. At the end of 2007, there were 5.7. million people living with HIV in South Africa and almost 1000 deaths occurring everyday (UNAIDS, 2008). This number is higher than in any other country in the world and is expected to double over the next decade. The country estimates that $18.3 \%$ of adults (15-49 years) are living with HIV (Department of Health, 2008).More than $55 \%$ of all South African infected with HIV reside in KwaZuluNatal and Gauteng provinces (Dorrington et, al, 2006).

KwaZulu-Natal province has recorded the highest HIV infection rate amongst antenatal clinic attendees in South Africa 
in 2006 with a rate of $39 \%$ as compared to eight other provinces. The statistics show that an estimated $38 \%$ of pregnant women aged from 25-29 are HIV infected, making this age group the group with the highest prevalence rate (Department of Health, 2008:4).

The HIV epidemic is also having a severe impact on maternal deaths in South Africa (Dilraj, Abdool Karim and Pillay, 2007:42). HIV data from antenatal clinics in South Africa suggest that the country's epidemic might be stabilizing, but there is no evidence yet of major changes in HIV-related behaviour (UNAIDS, 2008).It is estimated that 91,271 babies were infected with HIV via Mother to Child Transmission during 2002 (Department of Health, 2003:2). The findings reveal that every day in Africa, 1900 children acquire HIV infection from their mothers. (Ekoveri, Leroy and Viho, 2004:697).

In light of these high statistics, it becomes imperative that all pregnant women attending antenatal clinics receive voluntary HIV testing and counselling (VCT). Uninfected women also benefit from such programmes because they provide them with information to reduce the risk of acquiring HIV. For infected pregnant women, interventions can enable them to receive appropriate and timely help for their own health and to reduce the risk of passing the virus on to their babies (Semprini and Fiore, 2004).

\section{Problem statement}

Despite the rapid implementation of pilot health programmes, the uptake of services for the prevention of HIV infection from mother to child remains low in South Africa (Ekoveri 2004: 698). Many pregnant women believe that they are not at risk of HIV infection and do not know about the benefits of treatment and interventions available to prevent HIV transmission to their infants (Berer and Ray, 1993:239).

Studies reveal that there is a correlation between levels of knowledge about HIV testing and the chances of accepting the test. Fernandez et al. (2000: 467), found that acceptance was related to strong beliefs about the benefits of testing, knowledge about vertical transmission and the woman's perception that she is at risk of HIV infection (Kiarie et al. (2000:1468).Data from multitude of KAPB (knowledge, attitudes, practices, and behaviour) studies, demonstrate that most women have only a superficial knowledge of HIV testing (Goldman and Hatch 2000:424).

\section{Purpose}

The purpose of this study is to establish the knowledge and perceptions of pregnant women about HIV testing and to ascertain the level of HIV testing acceptability amongst these women

Objectives

The objectives for conducting this study were:

- To ascertain women's
knowledge of HIV testing
To describe women's
perceptions of HIV testing in
pregnancy
To determine factors relating to
acceptability of HIV testing by
pregnant women.

\section{Significance of the study}

The significance of this study is to find strategies that will make HIV testing in pregnancy more acceptable to pregnant women. There is hope that increased knowledge of HIV testing in pregnancy will allay anxiety in pregnant women thus increasing the number of women accepting HIV testing. The health sector may be able to plan and allocate the appropriate resources. This will serve as a way of evaluating health promotion programmes when the level of knowledge and perceptions of pregnant women are known.

\section{Theoretical Frame work}

The researcher used the Health Belief Model (HBM) and the Reasoned Action Theory to support the rationale for conducting the study. Research around health-related issues has indicated that people need to take reasoned action in order to stay healthy.

Maiman and Becker (1974) formulated the Health Belief Model to predict health related behaviour in terms of certain belief patterns. It focuses on the perceptions and beliefs of individuals and in so doing, it tries to explain and predict health behaviours (Dawad 2003). This model is based on the premise that the individual's health behaviour is a function of the perceived threat and the perceived benefit (Rawjee 2002:16). The model maintains that an individual's perception of susceptibility, severity, benefits, barriers and the cures available determine the possibility of the individual engaging in preventative health activity.

This is illustrated diagrammatically in figure 1 .

\section{Literature Review}

Pregnant women endorse the offer of HIV testing, but they are uncertain about personal uptake (Johnson and Johnstone, 1993:21). This means that women offer to take HIV testing but they are not sure whether they really want to take the HIV test. They are also not sure how are they going to cope with the results if they are positive.

HIV testing and counselling in pregnancy HIV counselling is a confidential process that enables individuals to examine their knowledge and behaviour in relation to their personal risk of acquiring or transmitting the HIV virus. Counselling helps them to decide whether or not they should be tested. One in three babies born to HIV infected mothers will be infected with HIV during pregnancy, delivery and via breast milk without intervention. All mothers should be offered voluntary counselling for HIV during antenatal care (Department of Health, 2008).

\section{Knowledge of HIV testing}

To reduce maternal transmission, high quality, appropriate information and counselling must be provided to ensure that patients are able to make informed decisions before and after testing. Lack of adequate information, knowledge about HIV testing and counselling increases ignorance and promotes stereotypes about HIV/AIDS. Women who acquire better knowledge on Mother to Child Transmission are more likely to take the test (Ho and Loke, 2003: 823). According to Kalichman and Simbayi (2003:446), knowledge appears to be a precursor to reducing stigma.

Katzenllenbogen, Joubert and AbdoolKarim (1999), are of the opinion that individual health related behaviour is influenced by the knowledge of the disease and necessary promoting actions to prevent or improve the condition, as well as their beliefs, which may be positive or negative towards the disease or health promoting actions.

\section{Perceptions on HIV testing}

HIV risk perceptions are not stationary and can vary depending on the context, time and knowledge of the person 


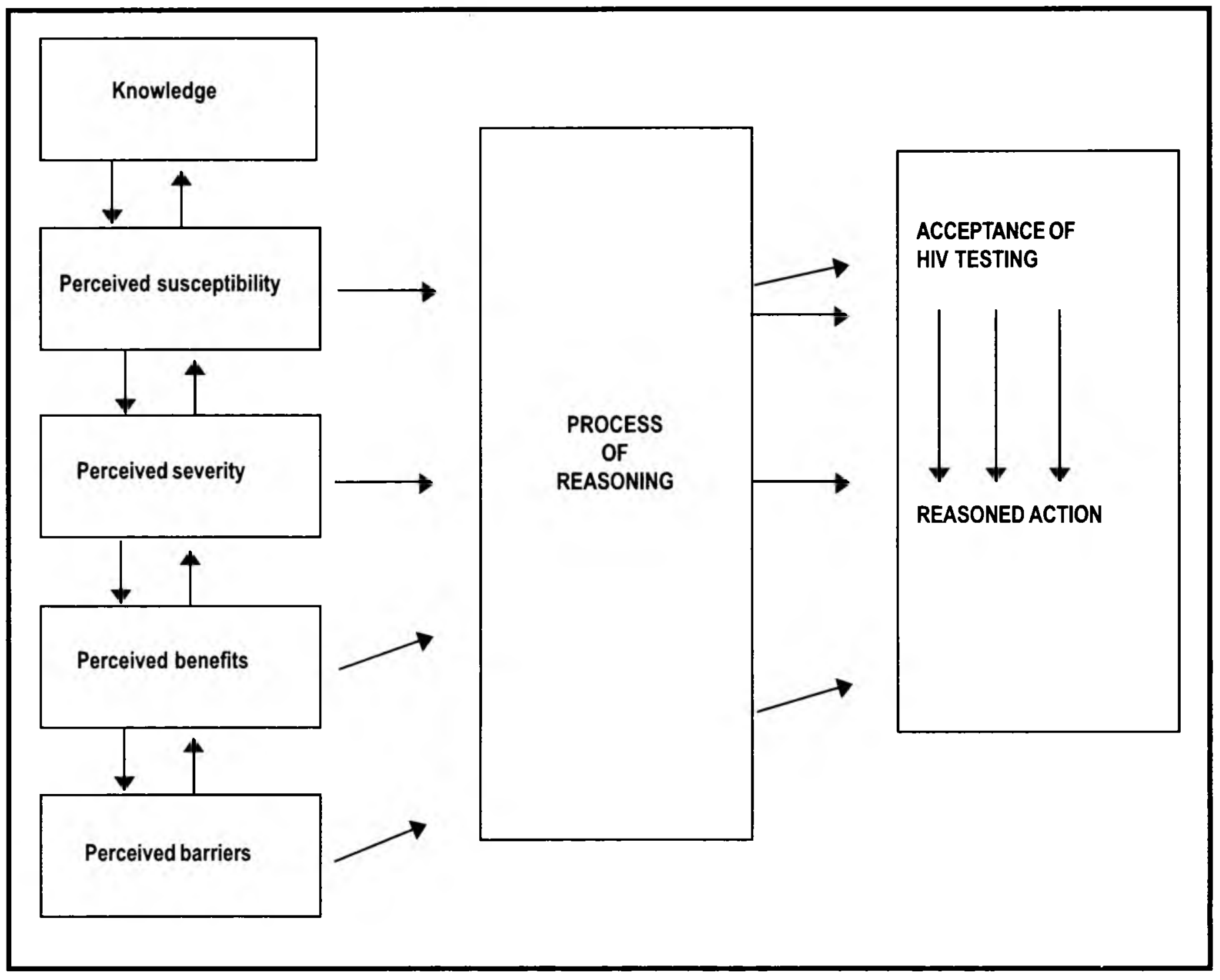

involved (Dawad 2003:13). People, who are exposed to the same or a similar situation, may have different perceptions of risk at different stages of

\section{Acceptability of HIV testing}

The problem of HIV/AIDS is not only for underdeveloped countries. Developing and developed countries are experiencing the problem of the acceptability of voluntary HIV testing as discussed by Cartoux et al (1998:2498).Goldman and Hatch $(2000: 425)$ are of the opinion that knowledge and good perceptions of HIV testing are a prerequisite for increasing the acceptability of HIV testing. Nakchbandi et. al.(1998:762), found that acceptance of HIV testing among pregnant women increased when testing was offered with counselling and that outreach and educational efforts substantially improve the acceptance of HIV testing.

\section{Methodology}

This is a quantitative study. The researcher used an exploratory survey to obtain facts in an attempt to learn about and describe the perceptions and knowledge pregnant women have on HIV testing. An exploratory survey explores the characteristics of the target population and identifies what issues are important to their understanding of the topic (Katzenellenbogen, et. al 1999:170).

\section{Setting}

The antenatal clinic where the study was conducted is The eNdondakusuka Municipality, Northern KwaZulu-Natal. This Community Health Centre is in the Ilembe District. The clinic conducts a weekly ante-natal clinic, which is held on a Monday. Out of 200 pregnant women who are seen per month, only $10 \%$ opt for HIV testing.

\section{Population}

The population surveyed was made up of pregnant women attending the antenatal clinic at the selected clinic for the first time in their current pregnancy. The reason for testing pregnant women for HIV, according to Johnson and Johnstone (1993:16) is that reproduction and childbearing decision-making focuses on women.

\section{Sampling method}

This study used systematic sampling to draw its sample from the population. The inclusion criterion for the study was that the pregnant woman should be attending antenatal clinic for the first time in her current pregnancy. All pregnant women who come to the clinic are entered in the register for statistical purposes. The antenatal register was used as the sampling frame. The population elements for the day were listed in consecutive 
numbers. In the list, the research selected every third name and $20 \%$ was selected each Monday over a period of four weeks. This means that there were 10 respondents each week making a total of 40 respondents in four weeks.

\section{Data collection}

Data was collected each Monday over one month in November 2004. The researcher used self-administered questionuaires for collecting data with close-ended questions. No names were written on the questionnaires. Anonymity was maintained and participants were guaranteed confidentiality

\section{Instrument}

The questionnaire was translated into Zulu since the majority of participants were Zulu speaking .The translated questionnaire was tested by an expert in the School of Nursing for content validity Section $A$ of the questionnaire covered demographic data such as age. educational level. parity and marital status. Section B contained questions to ascertain the knowledge levels of respondents regarding HIV. Section C and $D$ dealt with the respondent's perception towards testing for $\mathrm{HIV}$.

\section{Data collection process}

The researcher waited for the pregnant women to receive health education. group counselling and the antenatal examination. Informed written consent was obtained before questionnaires were administered. Data was collected in a private room adjacent to the waiting area. Only one participant was allowed in the room at any one time to maintain confidentiality.

\section{Ethical consideration}

Permission for the study was sought from the following bodies:

- University of KwaZulu- Natal
Research Ethics committe
Deprartment of Health head
office.
Nurse Manager at Community
Health centre
Pregnant women attending the
clinic

\section{Validity}

Validity refers to the degree to which an instrument measures what it purports to measure (Polit and Hungler. 2001). In this
Figure 1. Age Distribution ( $n=40$ )

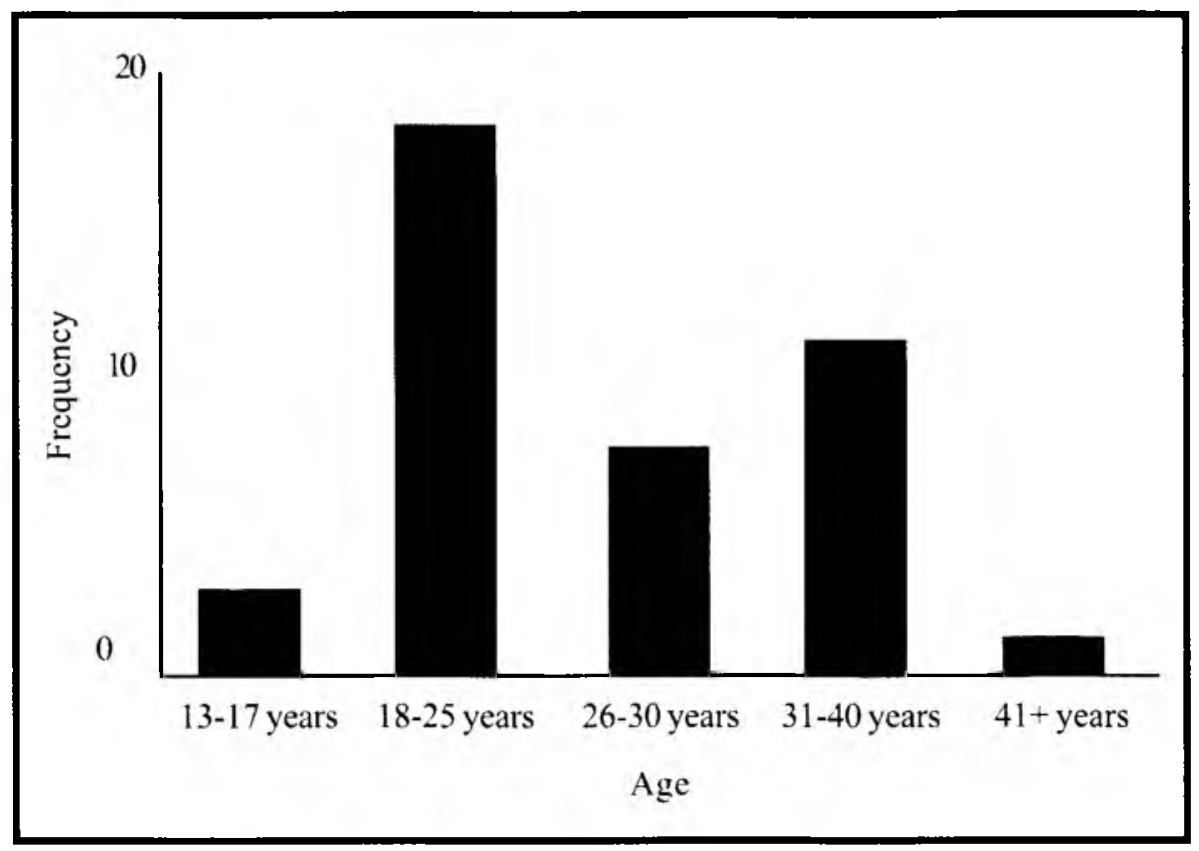

study the instrument actually measured the knowledge, acceptability and perceptions of pregnant women towards HIV testing.

\section{Content Validity}

The research questions in the questionnaire covered the content of the research in terms knowledge, perception and acceptability of HIV testing.

\section{Reliability}

A pilot study was conducted on a group of five pregnant women who did not form part of the study. They were given a questionnaire to complete before HIV counselling at the clinic. An appointment was made with the respondents to come to the antenatal clinic a week later so that they could complete the questionnaire again with the same questions. The responses from the first questionnaire and the second questionnaire were the same and there was correlation.

\section{Data Analysis Introduction}

Data was analysed using Statistical Package for the Social Sciences (SPSS) 11.5 for Windows. Forty questionnaires were distributed and they were all returned because the researcher personally distributed and collected them. The researcher used frequency. distributions to describe the demographic profile of the respondents and to characterise women's acceptance. perceptions and knowledge of HIV testing in pregnancy.

\section{Results \\ Demographic Characteristics of Respondents}

\section{Distribution of respondents by Age}

The results in figure 1, revealed that most women were relatively young, between the age of $18-25(45 \%, n=18)$. Twenty seven and half percent $(n=11)$ of women were between the ages of 31-40.17.5\% $(n=7)$ were between $26-30.7 .5 \%(n=3)$ were between 13-17 and with a relatively small number of women who were 41 years or older which is $2.5 \%(\mathrm{n}=1)$.

\section{Distribution of respondents by Marital Status}

The highest proportion of respondents were unmarried $\left(90^{\circ}, 0, n=36\right)$. There were only $7.5 \%(n=3)$ married women in the sample. Many women were single and young. According to Baylies and Bujra (2000:10). these young patients have limited information about reproductive and sexual health including HIV/AIDS and they engage in sexual relationships at an early age. Ho and Loke (2003: 822). in their study found that unmarried women were more likely to be tested for HIV.

\section{Distribution of respondents by parity}

Seventy percent $(n=28)$ of respondents were of parity between p0-p2. 20\% $(n=8)$ were of parity between p3-p5. Only $10^{\circ} \%$ 
Figure 3. Marital Status of Respondents. $(n=40)$

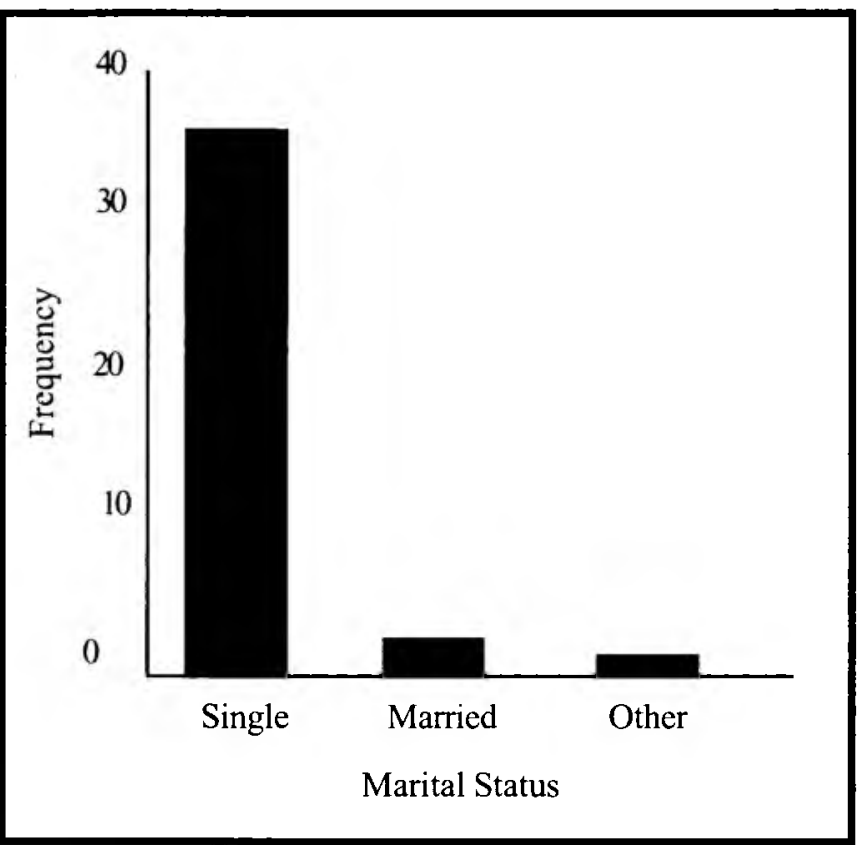

one needed to practice safe sex when tested negative $(47.5 \%$, $\mathrm{n}=19)$. Thirty five percent $(n=14)$ were of the opinion that the person needed to retest to be sure and $17.5 \%(n=7)$ said the person needed to be careful.

The responses of the respondents is consistent with what is said by Kennedy (2003:76) that discussion and counselling following a negative result should include information positive test results to a person requires great.

Would you tell another person about the importance of testing?

Seventy percent $(\mathrm{n}=28)$ of women said they would convey the message regarding the importance of testing to another person while $17,5 \%(\mathrm{n}=7)$ said they would not be able to tell another person and $12.5 \%(n=5)$ were not sure. In order to increase the percentage of people who felt able to convey the message of the importance of HIV testing in pregnancy, all health sectors providing VCT services must make every effort to provide VCT services that women see as clearly beneficial.

Have you ever had an HIV test?

Eighty five percent $(n=34)$ of women $(n=4)$ of respondents were between parity six and above.

\section{Educational standard}

The results revealed that only $10 \%(n=4)$ of respondents had tertiary education. The highest, $62.5 \%(\mathrm{n}=25)$ proportion of the sample had secondary education .There was only one $(2.5 \%)$ respondent with no formal education. The sample consisted mostly of women with low levels of education. The researcher is of the opinion that women with less education have little access to information

\section{Knowledge of HIV testing Who should test for HIV?}

Forty percent $(n=16)$ of women were of the opinion that testing should be done by all women together with their partners .Only $7.5 \%$ agreed that testing should be done by all women. Women studied by Matinga (2003:11), felt that HIV counselling and the testing process would be meaningful if couples are involved.

\section{When should a person test?}

Fifty five percent $(n=22)$ of respondents, responded by saying a woman should take a test when she wanted to. Twenty seven and a half percent $(n=11)$ said she should test during pregnancy and only $15 \%(n=6)$ said she should test when asked by a health worker.

\section{If you have tested negative, what must you do?}

Most women responded by saying that

\section{Figure 5. Educational standard ( $\mathrm{N}=40)$.}

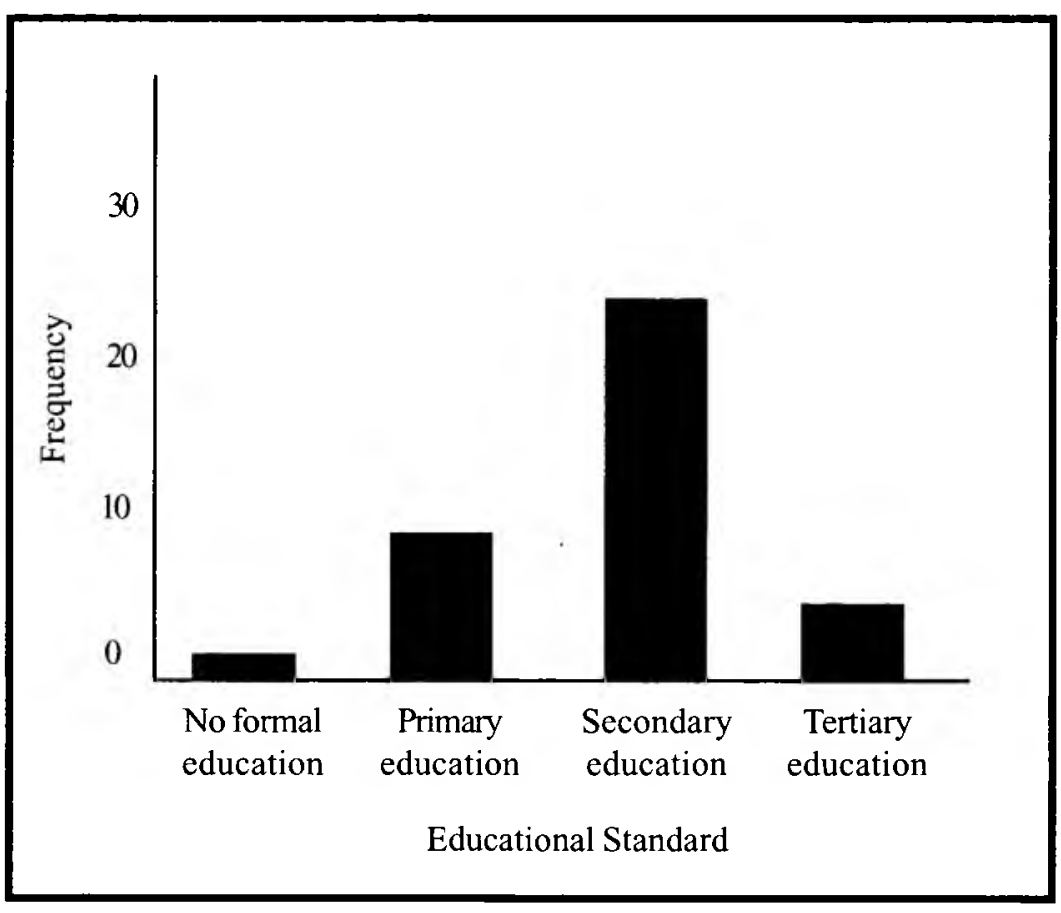

about the window period and the possibilities of further exposure.

\section{If you have tested positive, what must you do?}

Most respondents $(45 \%, n=18)$ were of the opinion that the person must use a condom. Twenty percent were of the opinion that the woman must abstain from sex and another $20 \%$ said the woman must take medicine. The respondents were asked to specify the medicine and they said the woman should take AZT. Six percent $(n=3)$ of respondents said the woman should inform her partner of her test result. Breaking the news of HIV have not had an HIV test before. When asked if they would like to be tested, only $52.5 \%$ respondent by saying they would like to take the test and $32.5 \%(\mathrm{n}=13)$ said they would not take the test. This shows that the uptake of HIV testing in pregnancy is still low. Fifteen percent $(n=6)$ said they had already had the HIV test

\section{Does testing benefit a pregnant woman?}

Thirty five $(87.5 \%)$ women were of the opinion that testing does benefit a pregnant woman. Only one $(2.55 \%)$ respondent had a different view and said 


\begin{tabular}{|c|c|c|c|c|c|c|c|c|c|c|c|}
\hline & \multicolumn{2}{|c|}{$\begin{array}{l}\text { St rong I y } \\
\text { Agree } \\
\text { N } \%\end{array}$} & \multicolumn{2}{|c|}{ Agree } & \multicolumn{2}{|c|}{ Not Sure } & \multicolumn{2}{|c|}{ Disagree } & \multicolumn{2}{|c|}{$\begin{array}{l}\text { Strongly } \\
\text { Disagree }\end{array}$} & Total \\
\hline $\begin{array}{l}\text { Testing is a routine way of } \\
\text { monitoring pregnant women }\end{array}$ & 9 & 22.5 & 17 & 42.5 & 8 & 20 & 3 & 7.5 & 3 & 7.5 & 40 \\
\hline Testing promotes condom use & 15 & 37.5 & 17 & 42.5 & 2 & 5.0 & 6 & 15.0 & 0 & 0 & 40 \\
\hline $\begin{array}{l}\text { Testing is for the safety of the } \\
\text { unborn baby }\end{array}$ & 22 & 55.0 & 11 & 27.5 & 3 & 7.5 & 4 & 10.0 & 0 & 0 & 40 \\
\hline $\begin{array}{l}\text { Testing is for health workers to } \\
\text { conduct research }\end{array}$ & 4 & 10.0 & 10 & 25.0 & 13 & 32.5 & 10 & 25.0 & 3 & 7.5 & 40 \\
\hline $\begin{array}{l}\text { Testing will provide mothers } \\
\text { with earlier access to treatment }\end{array}$ & 24 & 60.0 & 11 & 27.5 & 3 & 7.5 & 2 & 5.0 & 0 & 0 & 40 \\
\hline $\begin{array}{l}\text { All women who receive prenatal } \\
\text { care should be tested for HIV }\end{array}$ & 19 & 60.0 & 14 & 35.5 & 4 & 10.0 & 2 & 5.0 & 1 & 2.5 & 40 \\
\hline $\begin{array}{l}\text { Testing will minimize the number } \\
\text { of HIV infected babies }\end{array}$ & 15 & 37.5 & 20 & 50.0 & 3 & 7.5 & 0 & 0 & 2 & 5.0 & 40 \\
\hline $\begin{array}{l}\text { Getting tested is emotionally } \\
\text { stressful }\end{array}$ & 13 & 32.5 & 9 & 22.5 & 4 & 10.0 & 10 & 25.0 & 4 & 10.0 & 40 \\
\hline $\begin{array}{l}\text { Testing is a way to decrease } \\
\text { anxiety about HIV }\end{array}$ & 9 & 22.5 & 19 & 47.5 & 6 & 15.0 & 5 & 12.5 & 5 & 12.5 & 40 \\
\hline $\begin{array}{l}\text { Testing does not eliminate } \\
\text { current or future risk of HIV } \\
\text { infection }\end{array}$ & 9 & 22.5 & 13 & 32.5 & 12 & 30.0 & 6 & 15.0 & 0. & 0 & 40 \\
\hline
\end{tabular}

that testing did not benefit the pregnant woman. The reason stated was that, if the woman is tested, sometimes testing causes misunderstanding in families.

The table lindicated some of the perceptions stated by pregnant women

\section{Discussion}

\section{Age and Marital Status}

The sample in this study was found to be mostly young women between the ages of $18-25(45 \%)$ and most of them were unmarried $(90 \%)$. The reason why there are such a high proportion of single pregnant women is that the area where the study was conducted is an industrial area. The other reason is that, during these years (18-25) young women learn, explore and make decisions that will affect the rest of their lives including early and unintended pregnancies (USAID 2004). Enosolease and Offor (2004) further found that older women were more likely to accept HIV testing than the young ones. This may be due to the fact that older women see themselves at risk of contracting HIV infection.

\section{Educational Standard}

Most women in the study had attained secondary school education $(62,5 \%)$ and only $10 \%$ had attained tertiary education. This is in line with the findings of Baylies and Bujra (2000:6) where they found that, women's lack of access to education and lower levels of literacy contribute to their limited access to information about HIV testing.

\section{Unemployment}

The majority of young women migrate from their homes to seek employment in the low paid industries. Because they are financially dependent, they fail to control their sexual lives and they engage in unprotected sex. Enosolease \& Offor (2004:88), in their study found that young women had multiple sexual partners and regularly practised unprotected sex. This increases their vulnerability to HIV/AIDS and the death toll among economically productive people is increasing (Davhana- Maselesele, Lalendle \& Useh, 2007:17)

\section{Willingness to test}

In this study, $52,5 \%$ of women were willing to be tested out of the $85 \%$ who had not been previously tested. This is considered as a low HIV testing acceptance. In a study conducted by Ho and Loke (2003:823), they found that pregnant women refused the HIV test mainly because they have only one sexual partner who they believe is trustworthy and they feel that being infected with HIV is out of question. The majority of young women migrate from their homes to seek employment in the low paid industries. Because they are financially dependent, they fail to control their sexual lives and they engage in unprotected sex. Enosolease and Offor (2004:88), in their study found that young 
women had multiple sexual partners and regularly practised unprotected sex. This increases their vulnerability to HIV/ AIDS.

According to this study, the poor response appeared in the population where only $15 \%$ reported to have ever been tested for HIV. This low figure is likely to be influenced by past exposure to HIV testing in their previous pregnancies and by the acceptability of the voluntary counselling and testing provided.

\section{Perceptions}

The findings showed that $93 \%$ of women said testing was a good idea and $85 \%$ said it was necessary. However, not all women who said HIV testing in pregnancy was a good idea thought it was necessary because $52,5 \%$ said that they would opt for HIV testing.

Exner (2002:7) and Matinga (2003:7) found that women felt that being tested was a way to decrease their anxiety about HIV. This is further supported by the findings of this study where the highest population $(55 \%)$ of women felt that getting tested for HIV is emotionally stressful.

These findings highlight the importance of using pre-test counselling to directly address patients' anxiety about testing. Most of the women felt that HIV testing should be routinely done. The findings of this study are similar to the findings of the study conducted by Kiarie et al (2000: 1469), where most women felt that HIV testing should be routinely offered in antenatal clinic because it climinates the need for a woman to be singled out for testing and therefore reduces the suspicion of spouses and friends.

They further found that the contributing factor in the women's acceptance of HIV testing was based on the women's perception of the benefit for their babies or their own health of having the test.

\section{Future Reproduction for an HIV Positive Woman}

For African women children are considered essential to self -fulfilment and to family happiness (Tallis, 1997:19) and the value placed on children are high. The majority of women in the study $(62,5 \%)$ felt that an HIV positive mother should not bear children. The researcher argues that denying an HIV positive mother the right to bear children will be unconstitutional and it violates women's equality and their security as a person.

An individual woman's reproductive choices should be respected, regardless of her HIV status. It is their right to bear children but counselling is very important so that they make informed choices. Women must decide on their own without pressure to have or not to have a test.

\section{When should testing be done?}

The problem with testing a woman during pregnancy is the uncertainty about whether pregnancy is the best time for a woman to find out she is HIV positive. Kennedy (2003:65) recommended that if testing is done during pregnancy, it should be done at an early stage it possible because this would allow those women diagnosed as HIV positive the opportunity to be offered advice and treatment during antenatal care for their own health and that of their babies.

\section{Testing Negative}

Women $(47.5 \%)$ in this study were of the opinion that a person needed to practise safe sex when tested negative and 35\% said a person needed to retest to be sure and $7 \%$ said a person needed to be careful.

It is important to inform the woman that her negative results do not automatically indicate that her partner is negative. The counsellor must use this opportunity to encourage behaviour change and to ensure that the individual realises the limitations of a negative results. Counsellors also need to explain that a negative test result can only rule out past risk and is not the end point of HIV prevention. According to Kennedy (2003:76) a number of women will remain anxious following a negative result and they have been termed the worricd well.

\section{Testing HIV positive}

Eighteen (45\%) respondents in this study were of the opinion that if a person has tested HIV positive, she must use a condom in all future sexual encounters. Twenty percent $(n=5)$ said the person must take medicine. It is interesting to discover that there are some people who have knowledge about the availability of antirctroviral drugs. Condom use is not guaranteed for African women, this has been confirmed by studies which revealed that there is social stigma associated with the use of condom by women. FrancisChizororo \& Natshalaga (2003:110) found that $80 \%$ of women said they would have to first get permission from their partners to use the female condom.

\section{Sharing the results with other people}

The findings of this study reveal that the majority of respondents are not comfortable with informing relatives or partmers about their HIV test results. Ekanem \& Gbadegesin (2004:95) found that only few pregnant women would undergo the test if the results were to be shared with relatives. HIV positive women who communicated their results to partners often suffered violence from their partners after counselling (Temmerman, et al 1995: 970). A different view was put forward by Sethosa and Peltzer (2005:39) who stated that individuals who were aware that they are infected with HIV and who engage in sexual relationship have a social and legal responsibility to disclose their infections to their partners.

\section{Limitations of the study}

- This was a small-scale study and the results cannot be generalized.

- $\quad$ Study participants were only Africans and from one Community Health Centre. Therefore caution must be taken in generalizing the study results to other geographic regions and demographic groups.

\section{Recommendations related to research}

- A similar study need to be done on a larger scale so that results will be generalizable.

\section{Recommendations related to practice}

\begin{tabular}{|c|c|}
\hline & $\begin{array}{l}\text { Mutual testing must be } \\
\text { promoted which will support the } \\
\text { disclosure of HIV status and } \\
\text { allow the patient to get the } \\
\text { cmotional support needed. }\end{array}$ \\
\hline • & $\begin{array}{l}\text { HIV testing should be } \\
\text { integrated in Reproductive } \\
\text { Health Services. }\end{array}$ \\
\hline . & $\begin{array}{l}\text { Destigmatization campaigns to } \\
\text { reduce stigma directed to } \\
\text { women living with HIV need to } \\
\text { be introduced. }\end{array}$ \\
\hline & $\begin{array}{l}\text { There must be an improvement } \\
\text { in physical structures, like }\end{array}$ \\
\hline
\end{tabular}


provision of adequate counselling rooms.

\section{Conclusion}

From the findings of this study it can be deduced that HIV testing acceptance is low in the setting where the study was conducted. The women's perceptions of HIV testing are good but they are not consistent with their behaviour. That means that the women's positive attitude towards HIV testing was not transformed into actual behaviour. Women showed a good understanding and knowledge of HIV testing in pregnancy but their knowledge did not increase the uptake of testing. This might be due to the increase in awareness of vertical transmission of HIV. Increasing knowledge about HIV transmission may decrease the stigma surrounding HIV infection and help to improve acceptance rate to HIV testing in pregnancy.

\section{Rerences}

BAYLIES, C \& BUJRA, J 2000: Aids sexuality and gender in Africa. Routledge. London.

BERER, M \& RAY, S 1993. Women and HIV/AIDS: An international resource book. Harper Collins Publishers. Pandora.

CARTOUX, M; MEDA, N; VAN DE PERRE, P; NEWELL, ML; DEVINCENZI, I \& DABIS, F 1998: Acceptability of Voluntary HIV testing by pregnant women in developing countries: An International survey. AIDS. 12(18): 2489-2493.

DAVHANA-MASELESELE, M; LALENDLE, LL \& USEH, U 2007: Knowledge, attitudes and practices related to HIV/AIDS among learners in Vhembe district of Limpopo Province. Curationis, 30 (3): 15-22.

DAWAD, S 2003: Knowledge, attitudes, risk perceptions and condom use among married men and women in Ntuzuma and KwaDumisa, KwaZulu- Natal. Unpublished Masters Thesis: University of KwaZulu-Natal.

DEPARTMENT OF HEALTH 2003. South Africa HIV/AIDS statistics. Pretoria.

DEPARTMENT OF HEALTH 2008 South Africa National HIV / AIDS statistics. Pretoria.
DILRAJ, A; ABDOOL KARIM, SS \& PILLAY, S 2007: Challenging racial stereotypying of AIDS in South Africa with prevalence of HIV pregnant women. South African Medical Journal. 97 (1): 42.

DORRINGTON, R; JOHNSON, L; BRADSHAW, D \& DANIEL, T 2006: The demographic impact of HIV /AIDS in South Africa. National and provincial indicators for 2006. Centre for Actuarial Science, South African Medical Research Council. Cape Town.

EKANEM,EE \& GBADEGESIN,A2004: Voluntary counselling and testing (VCT) for. Human Immunodeficiency Virus: A study on acceptability by Nigerian women attending antenatal clinics. African Journal of Reproductive Health. 8(2): 91-100.

EKOVERI, DK; LEROY, V \& VIHO, I 2004: Acceptability and uptake of a package to prevent mother-to-child transmission using rapid HIV testing in Abidan, Cote d'voire. AIDS. 18 (4):697699.

\section{ENOSOLEASE, ME \& OFFOR, E 2004:}

Acceptance rate of HIV testing among women seeking induced abortion in Benin City, Nigeria. African Journal of Reproductive Health. 8 (2):86-90.

EXNER, TM; HOFFMAN, S; PARIKH, K; LEU, CS \& EHRHARDT, AA 2002 HIV counselling and testing: Women's experiences and the perceived role of testing as a prevention strategy. Perspectives on Sexual and Reproductive Health. 34 (2): 76-83.

FERNANDEZ, MI; WILSON, TE; ETHIER, KA; WALTER, EB; GAY,CL\& MOORE, J 2000: Acceptance of HIV testing during prenatal care. Perinatal guidelines evaluation project. Public Health Report. 115(5): 460-468.

FRANCIS-CHIZORORO, M \& NATSHALAGA, NR 2003: The female condom: acceptability and perception among rural women in Zimbabwe. African Journal of Reproductive Health. 7(3):101116.

GOLDMAN, MB \& HATCH, MC 2000: Women and Health. Academic Press: New York.

HO, CF \& LOKE, AY 2003: Pregnant women's decisions on antenatal HIV. Hong Kong: AIDS Care. 15 (6): 821-827.

JOHNSON, MA \& JOHNSTONE, FD 1993: HIV infection in women. Church Livingstone. Edinburgh.

KALICHMAN, SC \& SIMBAYI, LC 2003: HIV testing attitudes, AIDS stigma and voluntary HIV Counselling and testing in black township in Cape Town, South Africa: Sexually Transmitted Infection. 79(96): 442-447.

KATZENELLBOGEN,JM; JOUBERT,G \& ABDOOL KARIM, SS 1999: Epidemiology: A manual for South Africa. Oxford University Press.

KENNEDY, J 2003: HIV in Pregnancy and Childbirth: Elsevier Limited. New York.

KIARIE, J; NDUATI, R; KOIGI, K; MUSIA, J \& JOHN, G 2000: HIV testing in pregnancy: acceptability and correlates of return for test results. AIDS. 14(10): 1468-1469.

LACHMAN, S 1995: Heterosexual: HIV/ AIDS as a global problem. A guide for medical practitioners and health care workers. The Natal Witness Printing and Publishing Co. Pietermarizburg.

MAIMAN, LA \& BECKER, MH 1974: The Health Belief Model: Origins and correlates in psychological theory. Health Education Monographs. 336-353.

MATINGA, PU 2003: Factors influencing pregnant women's decisionmaking for HIV testing in Southern Malawi. N.G.O Networks for Health.

NAKCHBANDI, IA; LONGENECKER, JC; RICKSECKER, MA; LATTA, RA; HEALTON, C \& SMITH, DG 1998: A decision analysis of mandatory compared with voluntary HIV testing in pregnant women. Annals of Internal Medicine, 128(91): 761-6.

POLIT, DF \& HUNGLER, BP 2001: Nursing research: principles and methods. J.B.I Lippincott Company: Philadelphia.

RAWJEE, VP 2002: Effective HIV/AIDS communication campaigns: A case study on an HIV/AIDS awareness campaign targeted at young adults at a tertiary institution: Masters Thesis: University 
of KwaZulu-Natal.

SEMPRINI, A \& FIORE, S 2004: HIV and reproduction. Obstetrics and Gynaecology, 16(3): 258-260.

SETHOSA, E \& PELTZER, K 2005: Evaluation of HIV counselling and testing, self disclosure, social support and sexual behavoir change among a rural sample of HIV reactive patients in South Africa. Curationis. 28 (1): 29-41.

TALLIS, VA 1997: An exploratory investigation into the psychosocial impact of an HIV positive diagnosis in a small sample of pregnant women with special reference to KwaZulu- Natal. University of KwaZulu-Natal. Durban.

TEMMERMAN,M;NDINYA-ACHOLA, J; AMBANI, J \& PIOT, P 1995. The right to know HIV test results. Lancet. 15(345): 969-70.

UNAIDS 2008. Report on global AIDS epidemic. Geneva. Available from http:// www.unaids.org. (Accessed 08 September 2008).

USAID 2004. USAID strategy in South Africa. Available from http:// www.usaid.gov. (Accessed 10 July 2004). 